\title{
Malnutrition Status of Adolescent Girls in India: A Need for the Hour
}

\author{
Deepika Anand ${ }^{1}$, R. K. Anuradha ${ }^{2}$ \\ ${ }^{1}$ Research Scholar, Department of Home Science, Sri Venkateswara University,Tirupati, A.P. India. \\ ${ }^{2}$ Associate Professor, Department of Home Science,Sri Venkateswara University,Tirupati, A.P. India.
}

\begin{abstract}
Adolescent girls form an important vulnerable and neglected sector of the Indian population. Adolescence is a transition phase through which a child becomes an adult. Specific nutritional needs and considerations are required for efficient growth and development. In India, adolescent girls suffer from various nutritional as well as non-nutritional problems.Freedom from malnutrition is a basic human right and their alleviation is a fundamental prerequisite for human and national development. Adolescent girls form an important vulnerable sector of population that constitutes about one-tenth of Indian population. About 30\% of India's population belongs to the adolescent age group of 10-19 years. The nutritional status of adolescent girls, the future mothers, contributes significantly to the nutritional status of the community. The purpose of this article is to emphasize on the prevalence of malnutrition status among adolescent girls and to summarize various nutritional problems faced by them in India.
\end{abstract}

Keywords: Malnutrition, Adolescent Girls, Vulnerable Sector, Nutritional Needs and Nutritional Problems.

\section{Introduction}

Adolescence is a period of transition between childhood and adulthood that occupies a crucial position in the life of human beings. This period is an important physiological phase of life characterized by an exceptionally rapid rate of growth and development both physical and psychological (Kumar S.P. et al., 2014). WHO defines adolescence as the segment of life between the age group of 10-19 years.Adolescenceisa transition phase through which a child becomes an adult. Specific nutritional needs and considerationsare required for efficient growth and development.The nutritional status of adolescent girls, the future mothers, contributes significantly to the nutritional status of the community.

Some 1.2 billion adolescents (10-19 years old) make up 18 per cent of the world'spopulation. More than half of all adolescents live in Asia. In absolute numbers, India is home to more adolescents - around 243 million - thanany other country. It is followed by China, with around 200 million adolescents. Theadolescent population of either of these countries dwarfs that of any other country. Adolescent girls form an important vulnerable sector of population that constitutes about one-tenth of Indian population. About 30\% of India's population belongs to the adolescent age group of $10-19$ years. Nearly $50 \%$ of adolescent girls aged between 15-19years are underweight in India(UNICEF, 2012).

Adolescents constitute a sizable proportion of the Indian mothers. However, despite adolescents being a huge segment of the population, policies and programme in India have focused inefficiently on the adolescent group. Nutrition plays a very important role in the physical, mental and socio-emotional development of adolescents.

\section{Nutritional Problems of Adolescents}

Adolescents experience intense physical, psychological, emotional and economic changes as they make the transition from childhood to adulthood (Lloyd et al., 2005).According to the National Family Health Survey-3 (NFHS-3, 2006) reports that in India 56\% of adolescent girls are anaemic, boys too are fallingprey to the disease. Around 30\% of adolescent boys suffer from anaemia.Psychological and behavioral problems also account for a considerable proportion of the morbidities. Fig1. depictsconceptual framework of nutritional problems and casual factors among adolescent girls. 


\section{International Journal of Science and Research (IJSR) \\ ISSN (Online): 2319-7064}

Index Copernicus Value (2013): 6.14 | Impact Factor (2014): 5.611

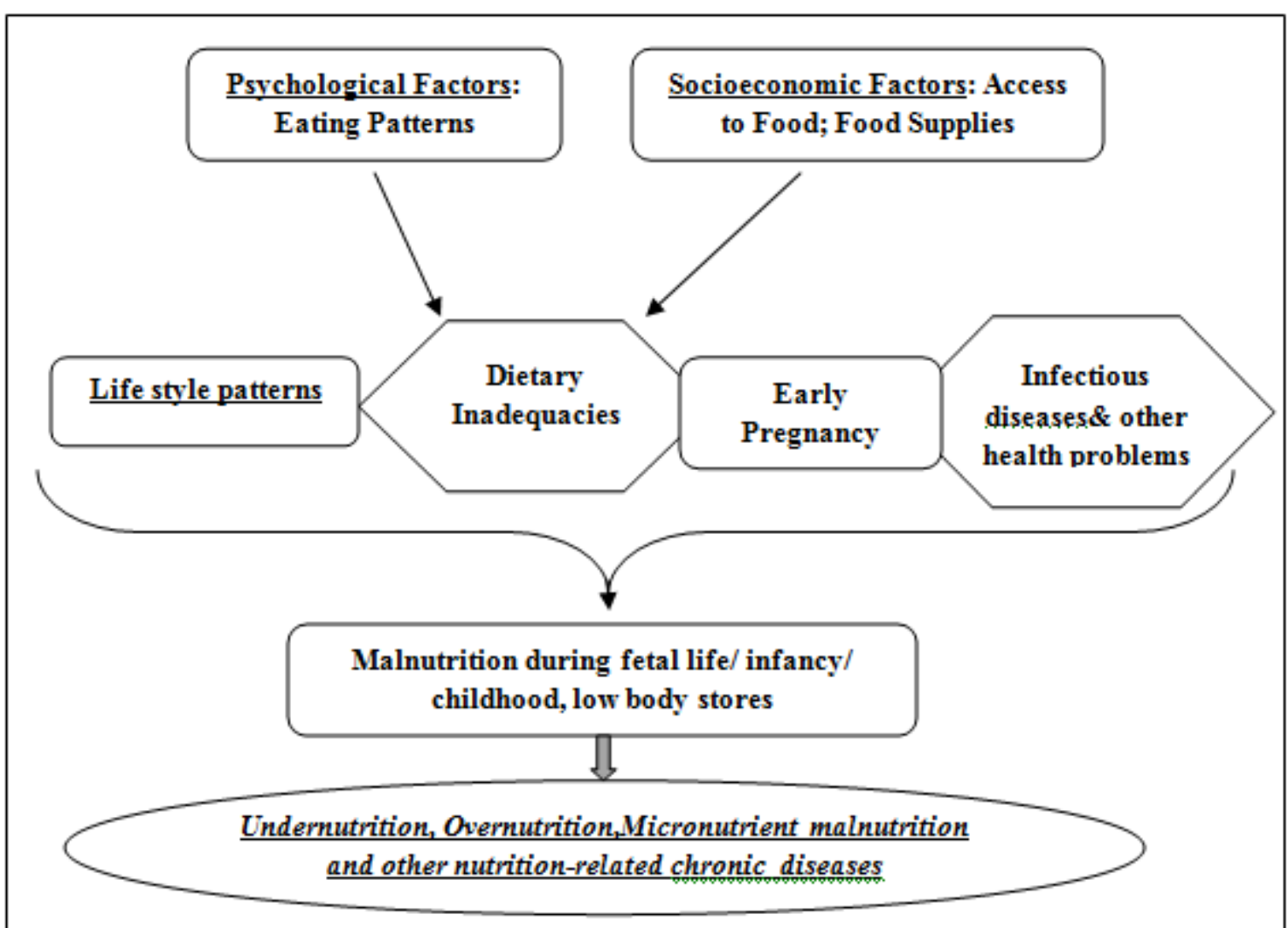

Figure 1: A conceptual framework of nutritional problems and casual factors among adolescent girls related to slowfetal growth and low birth weight (UNICEF,

Wasnik V. et al., (2012) reported that $56.4 \%$ girls were undernourished(BMI $<18.5 \mathrm{~kg} / \mathrm{m}^{2}$ ) while $5.8 \%$ were overweight (BMI > $\left.23.5 \mathrm{~kg} / \mathrm{m}^{2}\right), 16.7 \%$ showed reproductive problems, $30 \%$ of them showed clinical anaemia, 27.1 were having dental caries, $16 \%$ showed skin problems, 4\% showed eye problems (refractive error and defective vision), $2.4 \%$ showed UTRI and 2.1\% showed ENT problems.

\section{Undernutrition}

Nearly 50 per cent of adolescent girls aged 15-19 in India are underweight, with a body mass index of less than 18.5, and more than one quarter are underweight in 10 other countries. Such undernutrition renders adolescents vulnerable to disease and early death and has lifelong health consequences. In adolescent mothers, undernutrition is
2012).

Chronically malnourished girls are more likely to remain undernourished during adolescence and adulthood. Malnourished women are more likely to deliver low birth weight babies, who are prone to stunting. When stunted adolescents with decreased physical activity, inadequate fetal stores and increase risk to chronic diseases undergoes the phase of teenage pregnancy, they are more prone to malnutrition. Fig 2 depicts Intergenerational effect of malnutrition among adolescent girls. It's a viscous cycle of malnutrition. In order to break this intergenerational cycle, a special focus is needed to overcome adolescent malnutrition. The adolescent years, which have the highest growth velocity after infancy, have been highlighted as being more sensitive to environmental pressures than early development (Singhal A. et al., 2004). 
International Journal of Science and Research (IJSR)

ISSN (Online): 2319-7064

Index Copernicus Value (2013): 6.14 | Impact Factor (2014): 5.611

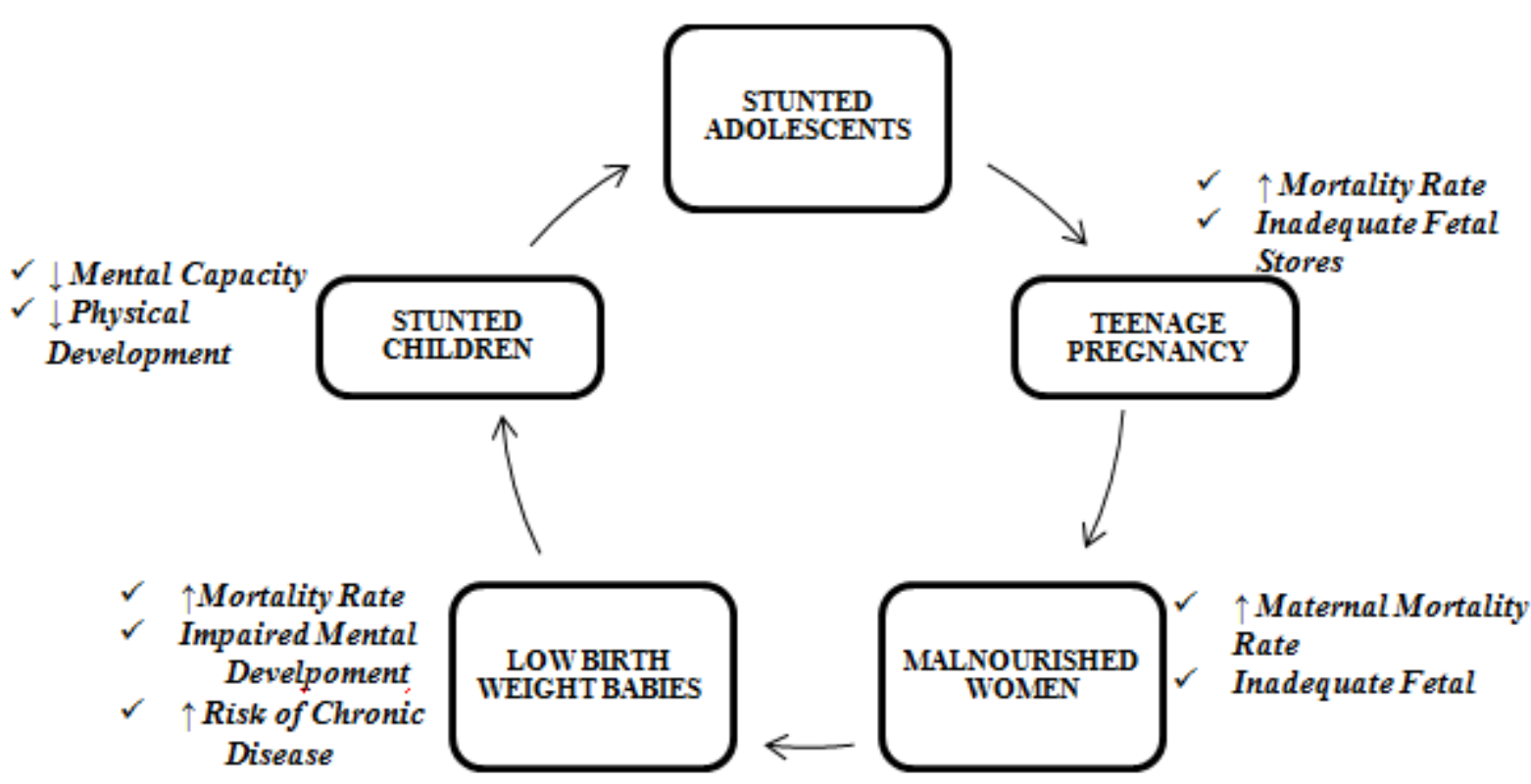

Figure 2: Intergenerational effect of malnutrition among adolescent girls

\section{Obesity}

Obesity is increasing in most of high income countries, in developing countries, undergoing nutrition transition and even in poor countries with current food insecurity and undernutrition problems. Obesity has a negative impact on life both in physical as well as psychological context. Adolescent obesity is one of the most serious health challenges of the $21^{\text {st }}$ century.Adolescents are exposed to high calorie, high fat foods that are readily available, heavily advertised and delicious. An excessive intake of calories is less often the cause than lack of excercise. Obese adolescent are extremely inactive and this fact may explain the reports that many overweight teenagers seems to consume fewer calories than normal weight controls, but the obese adolescent still eat more than that is needed for their scanty muscular work. Skipping meals at home and consuming junk foods also contribute to overweight. Obesity related symptoms in children and adolescents include psychosocial problems, increased cardiovascular risk factors, abnormal glucose metabolism, hepatic gastrointestinal disturbance, sleep apnoea and orthopedic condition.

\section{Micronutrient Deficiency}

In India, currently there is more emphasis on micronutrients as compared to macronutrients. This is because micronutrient deficiencies with respect to iron, vitamin A and iodine deficiency disorders continue to be major nutritional problems. Micronutrient deficiencies results from inadequate dietary intake, poor absorption of nutrients, excessive losses, increased requirements or a combination of these factors.

\section{Anaemia}

Nutritional anaemia is one the India's major public health problems. Incidence of anaemia in school age children tends to increase with age and correspond with acceleration in growth during adolescence. Globally, anaemia affects 1.62 billion people with about 69.4 million adolescents, 56 million pregnant women, and 468 million non-pregnant women estimated to be anaemic. Africa and Asia account for morethan 85 per cent of the absolute anaemia burden in high-risk groups and India is the worst hit, where more than than half of girls aged 15-19 are anaemic (UNICEF, 2012).There is a convincing evidence that iron deficiency and anaemia causes impaired growth, developmental delay, decrease physical activity, behavioural abnormalities, impairs cognitive function and school performance in adolescents.Fig 3 shows adverse effects of anaemia among adolescent girls.Iron deficiency in adolescent girls has serious implications on the future generation by adversely affecting the health of the foetus. Nearly one in every four adolescent girls aged 15-19 years in the developing world are married with South Asia the worst hit with 30 per cent of adolescent girls getting married at the age between 15-19 years (UNICEF, 2012). 


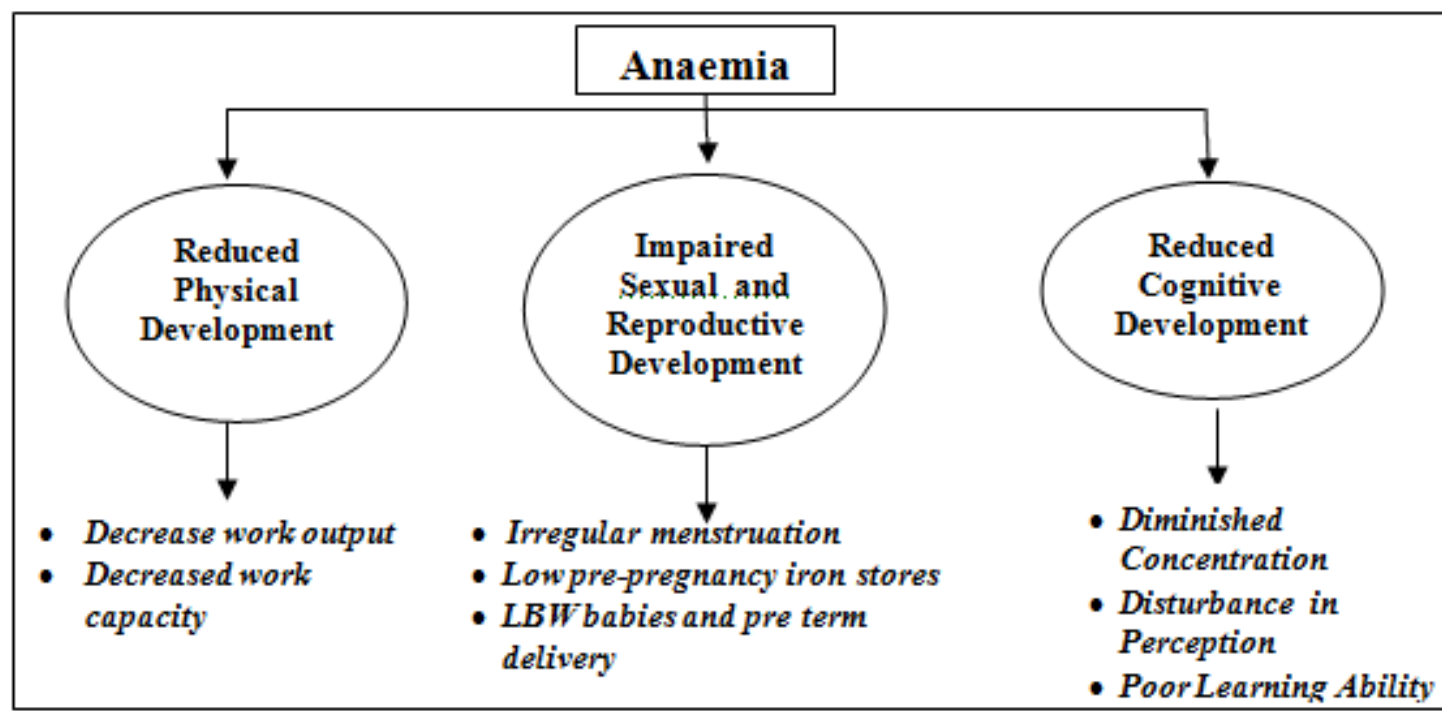

Figure 3: Adverse effects of anaemia among adolescent girls

\section{Vitamin A Deficiency}

Vitamin A Deficiency (VAD) is one of the most important causes of preventable childhood blindness and is a major contributor to morbidity and mortality from infections, especially in children and pregnant women, affecting the poorest segments of populations, particularly those in low and middle income countries. The primary cause of vitamin A deficiency is lack of an adequate intake of vitamin A, and may be exacerbated by high rates of infection, especially diarrhea and measles. Its consequence is most apparent during stages of life of high nutritional demand (WHO, 2009).

Vitamin A deficiency disorders(VADD) exists as a public health nutrition problem among preschool-aged children in 118developing countries worldwide, with the South-East Asian Region harboring the maximum number of cases. A cross-sectional study was undertaken by Agarwal A.K. et al., (2014) amongst school going adolescents aged between the age group of 10-19 years in rural areas of Bareilly district, to order to find out the prevalence of VAD ( bitot's spot and conjunctival xerosis) with its associated factors and to suggest the suitable measures to prevent VAD among them. The overall prevalence of VAD was found to be 42.22 per cent. It was higher in 15-19 years of age group adolescents (48.77 per cent) as compared to the age group of 10-14 years (41.6 per cent).

\section{Osteoporosis Risk}

Osteoporosis is a disease that affects many millions of people around the world. It is characterized by low bone mass and micro-architectural deterioration of bone tissue, leading to enhanced bone fragility and consequent increase in fracture risk.

Adequate calcium and vitamin D availability, together with regular physical activity, are among the most important environmental factors in the optimal accrual of bone mineral mass and density. Recent studies have pointed out the fundamental role of vitamin $\mathrm{D}$ in the development of strong bones. On the one hand, there is a growing awareness that the bone mineral mass acquired at the end of growth and development is a major determinant of the future risk of osteoporosis; on the other hand, the problem of osteoporosis is increasingly raised also in young patients.

\section{Discussion and Conclusion}

Adolescent girls' health plays an important role in determining the health of future population, because adolescent girls' health has an inter-generational effect. Adolescent girls are at high risk of iron deficiency and anaemia due to accelerated increase in requirements for iron, poor dietary intake of iron, high rate of infection and infestation as well as the social problems of adolescent pregnancy and conception. Chronically malnourished girls are more likely to remain undernourished during adolescence and adulthood. Adolescent girls are the mothers of tomorrow and no edifice can be built on a foundation which is so weak.

Adolescent girls form an important vulnerable and neglected sector of the Indian population. Guidance, counseling and imparting nutrition education can improve the dietary behaviour, which may further lead to promote sustainable development among adolescent girls.

\section{References}

[1] Agarwal A.K., Joshi H.S. and Singh A. 2014. Vitamin A deficiency among school going adolescents in rural areas of Bareily. European Journal of Nutrition and Food Safety. 4(4): 318-324.

[2] Kumar S.P., Nagarani R. and Rajendran A.K. 2014. A study on the prevalence of undernutrition among the rural tribal adolescent girls in Thiruvallur District, Tamil Nadu, South India. Int. J. Bio. Med. Res., 5(1): 38343836.

[3] Lloyd and Cynthia B. 2005. ed., Growing Up Global: The changing transitions to adulthood in developing countries, National AcademiesPress, Washington: 1.

[4] Ministry of Health and Family Welfare, Government of India.2005-2006. National Family Health Survey-III (NFHS-III), New Delhi, India. 


\section{International Journal of Science and Research (IJSR) \\ ISSN (Online): 2319-7064}

Index Copernicus Value (2013): 6.14 | Impact Factor (2014): 5.611

[5] Singhal A. and Lucas A. Early origins of cardiovascular disease: is there a unifying hypothesis. Lancet.2004; 363:1642-1645.

[6] United Nations Children's Fund (UNICEF). 2012. Progress for children: A report card on adolescents, April. New York. USA.

[7] WasnikV.B., RaoB.S. and RaoD. 2012.A study of health status of early adolescent girls residing in social welfare hostels in Vizianagaram District of Andhra Pradesh State, India.International Journal of Collaborative Research on Internal Medicine and Public Health. 4(1): 72-83.

[8] World Health Organization (WHO). 2009. Global prevalence of vitamin A deficiency in population at risk. Available from: http://www.who.int/vmnis/vitamina/prevalence/report/en.

\section{Author Profile}

Deepika Anand, Research Scholar, Department of Home Science, Sri Venkateswara University, Tirupati, A.P. India.

R. K. Anuradha, is Associate Professor, Department of Home Science, Sri Venkateswara University, Tirupati, A.P. India. 